\title{
El servicio público en el contexto constitucional y comunitario
}

\author{
José Luis Meilán Gil
}

Catedrático de Derecho Administrativo

Universidad de A Coruña

\begin{abstract}
SUMARIO: 1. PLANTEAMIENTO. 2. REFERENCIA AL SERVICIO PÚBLICO ANTES DE LA CONSTITUCIÓN DE 1978. 3. LA PERSPECTIVA CONSTITUCIONAL. 4. EL IMPACTO DEL DERECHO COMUNITARIO. 5. RECAPITULACIÓN.
\end{abstract}

\section{PLANTEAMIENTO}

El servicio público, como categoría jurídica, ha pasado por muy diferentes momentos en cuanto a su calificación. De ser una noción clave para la definición del Derecho administrativo al pronunciamiento de su defunción y de un respetuoso entierro acorde con su importancia histórica. En unos ordenamientos jurídicos no ha llegado a formularse como tal concepto jurídico, aunque nunca ha faltado su expresión sociológica. La existencia y un buen funcionamiento de unos servicios públicos constituyen una constante demanda de los ciudadanos, que los poderes públicos de una u otra manera deben garantizar.

La categoría es, en buena medida, deudora de Francia, por motivos inicialmente procesales, alimentada después por el devenir ideológico, cargado de preocupaciones sociales. En España, el nacimiento, la práctica y la regulación jurídica de los servicios públicos no sigue una trayectoria idéntica a la francesa. Y ambos países, como los demás miembros de la Unión Europea se encuentran ante un ordenamiento comunitario, centrado en el mercado y en la libre competencia, en principio contradictorio con el régimen jurídico público del tradicional servicio público.

En las líneas que siguen se pretende mostrar hasta qué punto pervive el servicio público como categoría jurídica y cuál es su funcionalidad actual en el ordenamiento español teniendo como punto de referencia inexcusable el contexto de la Constitución de 1978 y el europeo comunitario. 


\section{REFERENCIA AL SERVICIO PÚBLICO ANTES DE LA CONSTI- TUCIÓN DE $1978^{1}$}

Hay en la historia del concepto de servicio público en España como una esquizofrenia. Por un lado van las regulaciones generales o sectoriales que aluden a los servicios públicos y por otro van teoría y doctrina.

Expresada abreviadamente, esa historia está marcada por los siguientes hitos o fases:

$\left.1^{\circ}\right)$ El servicio público es sinónimo de actividad administrativa. Así aparece en un autor de mediados del siglo XIX, Oliván (los servicios públicos equivalen a la materia administrativa y corresponden a las diversas necesidades administrativas), y así aparece en la legislación financiera (Ley de 20 de febrero de 1850 sobre bases de la contabilidad general provincial y municipal), así como en la Ley de desamortización de 1 de mayo de 1855.

$\left.2^{\circ}\right)$ El servicio público aparece desde muy temprano ligado al concepto de obra pública, que es fundamental, como pone de manifiesto la legislación sobre ferrocarriles, una de las obras públicas de mayor trascendencia económica en el siglo XIX. La obra pública es la gran demanda de aquella sociedad. Lo que sucede es que la obra pública es susceptible de explotación. La obra pública se destina a un servicio, bien particular, bien general (Ley de 3 de junio de 1855). Unos años más tarde, en 1869, el código de comercio reconoce ya como equivalente la obra pública y servicio público. El predominio de la obra pública sobre el servicio público para justificar un régimen jurídico específico, exorbitante del Derecho privado, luce en la centenaria Ley de Obras Públicas.

$3^{\text {o) }}$ Mas adelante y como consecuencia de una pugna de competencias entre municipios y Estado sobre algunos servicios públicos, por ejemplo el de tranvías, se utilizará la relación del servicio con el dominio público para justificar la intervención de los municipios. El título habilitante de la competencia no sería el servicio público; aquél derivaría de la titularidad de las vías por donde discurrían o estaba instalado el servicio. Se trata de una importación parcial localizada y tardía. En 1856 el proyecto de código civil no recoge la alusión al servicio público al definir el dominio público, que aparece en el códi-

\footnotetext{
${ }^{1}$ Cfr. J.L MEILÁN GIL La cláusula de progreso de los servicios públicos, IEA, Madrid, 1968, Prólogo de J.L. VILLAR PALASÍ; y "El servicio público como categoría jurídica", en Cuadernos de Derecho Público, no2 (1997) pp. 75 y ss.
} 
go vigente de 1889. En 1877, en cambio, se definirá a los tranvías por referencia a las vías públicas².

$4^{\circ}$ ) La práctica de la Administración municipal demuestra con una enorme variedad, que no permite hacer generalizaciones, que la realización de actividades que más tarde se configurarán explícitamente como servicios públicos son objeto de contratos de distinta naturaleza, sin que se hubiese formulado previamente una declaración formal de que se trataba de un servicio público. El servicio público, como tal, no constituía, pues, un título habilitante de la intervención de la Administración municipal en el sentido de delimitar una actividad que se reservaba a aquélla y que pudiera ser después objeto de concesión a los particulares. El título para intervenir en la actividad se deducía o se identificaba con la atribución legal a los municipios de la competencia de velar por los "intereses de los pueblos"3.

$5^{\circ}$ ) Es en torno a 1924 cuando se ha consolidado la importación de la doctrina francesa del servicio público y cuando en la legislación española se realizan las primeras declaraciones formales de servicio público para referirse a determinadas actividades, como es el caso de lo servicios de agua, gas y electricidad. Sólo entonces el servicio público, como tal, aparece como el título habilitante de la intervención de la Administración pública.

Antes de la promulgación de la Constitución y, sobre todo, a partir de mediados del pasado siglo, en paralelo con la formulación de su crisis y el intervencionismo que justificó el concepto de "gestión económica de la Administración ${ }^{4}$, se realizaron numerosos esfuerzos en la doctrina por definir la categoría, que encuentran también proyección en la jurisprudencia. No es del caso reproducirlos ahora. Para lo que aquí interesa bastará con destacar algunas notas.

${ }^{2}$ Según la tesis de J.L. VILLAR PALASÍ (La intervención administrativa en la industria, Madrid, 1964, pág. 161) dominio público, obra pública y servicio público eran técnicas de mutuo apoyo.

\footnotetext{
${ }^{3}$ Como observa J.L. VILLAR EZCURRA (Servicio público y técnicas de conexión, Madrid, 1980 pp. 46 y ss) "la jurisprudencia y la legislación española de principios de siglo ofrecen un verdadero caos de sentencias y disposiciones dispersas donde se otorga la calificación de servicio público a las actividades más diversas". Unos ejemplos significativos en J.L. MEILÁN, La cláusula, cit. pp.12-15.

${ }^{4}$ J.L. VILLAR PALASÍ, "La actividad industrial del Estado en el Derecho administrativo", RAP, 3 (1950) pp. 53 y ss.
} 
Dentro de las actividades de la Administración se trata de una actividad de prestación, de la que es titular. Fundamental, por ello, es la publicatio, término acuñado y puesto en circulación con fortuna, por Villar Palasí. Resultaban conformes con lo que disponía el artículo 197 del Reglamento general de la ley de contratos del Estado de 1975, relativo al contrato de gestión de servicios públicos (en la actualidad artículo 155 de ley de contratos de la Administraciones Públicas). Antes de proceder a la contratación se requería declaración expresa de que la actividad "queda asumida por el Estado como propia del mis$m o$ ". Esa declaración implicaba que se refería a una actividad indispensable para la vida de la sociedad, que, obviamente, era deudora de una apreciación política.

Se trataba de una prestación regular y continua, con apoyo en el artículo 72 de la ley de contratos del Estado, de 1965, que tenía al público por destinatario, excluyéndose los servicios meramente internos de la Administración, a los que tenían por finalidad procurar rentas y por lo que se refiere al contenido de la actividad, aunque, no sin discusión, que fuera de carácter económico, que no implicase "el ejercicio de poderes soberanos" (art. 63 de la LCE o 157 de la LRL), ya que estaba implicado por medio la posibilidad de la gestión del servicio por particulares a medio de contrato o concesión.

Todo ello sometido a un régimen de Derecho público que no es cuestión de detallar, en cuanto a tarifas, "ius variandi", afectación de bienes, expropiación, responsabilidad y, también, a la adaptación al progreso, dentro de la potestad discrecional de la Administración para la organización de los servicios públicos.

No se consideran servicios públicos, en consecuencia, las prestaciones configuradas como funciones del Estado, aquellas cuya titularidad no corresponde en exclusiva a la Administración o no estén dirigidas al público, no exijan una continuidad regular o impliquen ejercicio de autoridad o coacción ${ }^{5}$.

\footnotetext{
${ }^{5}$ Estas eran las líneas generales de explicaciones teóricas en aulas universitarias que sintonizaban con las que, por escrito, expuso G. ARIÑO ORTIZ, Concepto de servicio público y bases de su régimen jurídico, Prelección, Universidad Complutense, 1.975, "El servicio público como alternativa", REDA, 23 (1979), pp. -546-553.
} 


\section{LA PERSPECTIVA CONSTITUCIONAL}

Una de las aportaciones sobresalientes de la Constitución es el papel central que atribuye a los derechos fundamentales ${ }^{6}$, que vinculan a todos los poderes públicos y cuyo contenido esencial debe ser respetado por el legislador (artículo 53,1), de clara influencia de la ley fundamental de Bonn, adelantada en la Ley para la Reforma política de 1977, en la que se incluyó una enmienda de la que tengo el honor de haber sido su promotor ${ }^{7}$.

En la Constitución española no aparece un concepto estricto de servicio público. Sólo indirectamente, como consecuencia del reconocimiento de los derechos fundamentales y libertades públicas -"reales y efectivas"- y de la referencia a la "libertad de empresa en el marco de la economía de mercado" (artículo 38), se producirá una reducción del ámbito de actuación del servicio público. En cuanto a las notas que la caracterizan no se produce variación.

Figura también, con un sentido amplio, como equivalente a actividad administrativa, a efectos de responsabilidad de la Administración, en el artículo 106.

Se habla de "servicios esenciales de la comunidad" en los artículos 28 y 37 al tratar del derecho a la huelga y del derecho de los trabajadores y empresarios a adoptar medidas de conflicto colectivo, para reconocer garantías que aseguren el mantenimiento o el funcionamiento de aquellos servicios. La misma expresión "servicios esenciales" existe en el artículo 128, que constituye el primero de los dedicados a "Economía y Hacienda". Su apartado 2 dice:

"Se reconoce la iniciativa pública en la actividad económica. Mediante ley se podrá reservar al sector público recursos o servicios esenciales, especialmente en caso de monopolio".

\footnotetext{
${ }^{6}$ Es muy ilustrativa la confesión de Jean RIVERO (Le conseil constitutionel et les libertés, Ed. Económica, $2^{a}$ ed., París, 1987, págs. 179-80) acerca de que "hasta un período reciente la noción de derechos fundamentales era totalmente ignorada del conjunto de nuestros derechos positivos" y por supuesto no evocada durante sus estudios de licenciatura.

${ }^{7}$ F. GONZÁLEZ NAVARRO, La nueva ley fundamental para la reforma política, Madrid, 1977, pp. 107-109. Pilar y Alfonso FERNÁNDEZ MIRANDA, Lo que el Rey me ha pedido, Barcelona 1995, p. 261, M. HERRERO DE MIÑÓN, en La transición democrática, Fundación BBV, Bilbao, 1999, Vol. I. p. 82.
} 
No se habla de servicios públicos, sino de reservar al sector público servicios esenciales. Traducida esta expresión en notas clásicas, definidoras del servicio público significa, en primer lugar, atribuir al Estado la titularidad en exclusiva de determinados servicios. No otra cosa creo que significa la reserva al sector público, por varias razones.

El reconocimiento de la posibilidad de que el Estado sea titular de actividades económicas está ya reconocido en el comienzo del párrafo 2.. tado. Con esto se deroga, por lo menos de una manera clara, el principio de subsidiariedad, que nunca estuvo plenamente vigente, aunque sí figuraba en parte del Derecho positivo español, según el cual el Estado no podría crear empresas públicas generalmente más que en defecto de iniciativa privada ${ }^{8}$.

El párrafo fue introducido por vía de enmienda "in voce", propuesta por el grupo socialista y apoyada por el centrista UCD, con el argumento de que el Estado cumple actividades que "no son estrictamente las de ocuparse de recursos esenciales”. La Constitución permite la creación de empresas públicas, con la única limitación de que deben operar dentro de la economía de mercado.

El sentido de la reserva al sector público de servicios esenciales se aclara teniendo en cuenta el iter del artículo. Inicialmente, sin el expreso reconocimiento de la iniciativa pública en la actualidad económica, fruto de una transacción parlamentaria, el artículo decía "la ley podrá reservar al sector público servicios públicos esenciales...”. Se trataba de una redacción muy similar a lo que dispone el artículo 43 de la Constitución italiana y tenía un precedente muy significativo en el artículo 44 de la Constitución española de $1931^{9}$.

En ambos artículos lo que se prevé, con una u otra expresión, trátese de reserva originaria o transmisión mediante expropiación (constitución italiana) o de nacionalización (Constitución española de 1931), es la asunción por el Estado de la gestión de servicios públicos, cuya titularidad correspondía al Estado. No es el caso del definitivo artículo 128 de la Constitución vigente. La reserva se entiende como atribución de titularidad sobre un servicio esencial.

\footnotetext{
${ }^{8}$ Cfr. J. L. MEILÁN, "Cuestiones institucionales de la empresas públicas en España” en La empresa pública, Studia Albortiana, 1970. También Empresas públicas y turismo, Madrid, 1967.

9 "Los servicios públicos y explotaciones que afecten al interés común pueden ser nacionalizados en los casos en que la necesidad social así lo exija”.
} 
Así quedó de manifiesto en el debate parlamentario. No es necesaria la reserva al sector público de servicios que tienen ese carácter, porque "precisamente es su titularidad por cualquiera de las Administraciones Públicas lo que dota del carácter de público al servicio ${ }^{10 "}$.

La Constitución española proporciona argumentos sólidos para la configuración del servicio público basado en las notas de titularidad en exclusiva de la Administración de unas actividades que, por su carácter de esenciales para la comunidad, y con el límite de la garantía constitucional de la libertad de empresa y la economía de mercado, son sustraídas de la titularidad originaria de los particulares.

Reconocida la iniciativa pública en materia económica, no tendría sentido reservar al sector público determinadas actividades si ello no significase la titularidad en exclusiva del Estado y sin la competencia con actividades paralelas de los particulares ${ }^{11}$.

Porque es así, el propio artículo 128 limita los supuestos de esta atribución exclusiva de la titularidad del Estado al ámbito de unas determinadas actividades de prestación que se configuran como servicios esenciales. Justamente por esta esencialidad, la Administración no podrá abdicar de la responsabilidad de garantizar el servicio aunque pueda, por supuesto, encomendar su gestión a los particulares, mediante concesión o cualquier otra fórmula equivalente. Los servicios públicos son servicios esenciales, aunque no todos estos son servicios públicos. Por eso no tiene sentido, aunque en algún caso se utilice, la expresión "servicio público esencial ${ }^{12 " . ~}$

${ }^{10}$ Cfr. Constitución española, Trabajos parlamentarios, II. p. 2326.

11 Así se manifiesta la legislación y la jurisprudencia. En ese sentido, el artículo 69 de la Ley 16/1987 de ordenación de los transportes terrestres dice que "los trasportes públicos regulares permanentes de viajeros de uso general... tienen el carácter de servicios públicos de titularidad de la Administración”.

La STS de 24 de octubre de 1989 (Ar. 8390), al interpretar qué sean bienes municipales destinados al servicio público, considera éste "como una actividad cuya titularidad ha sido reservada en virtud de una ley a la Administración, para que ésta la reglamente, dirija y gestione, en forma directa o indirecta y a través de la cual se presta un servicio al público de forma regular y continua”. En la línea de la explicación expuesta antes de la C.E., como la S.T.S. de 2 de marzo de 1979 (Ar. 1175).

12 Ad exemplum, Estatuto de la Radio y la Televisión, aprobado por ley 10 de enero de 1980: "la radiodifusión y la televisión son servicios públicos esenciales cuya titularidad corresponde al Estado" (art. 1,2). También R.D.L. 2/1986 de 23 de marzo sobre servicio público de estiba y desestiba $\left(\operatorname{art} .1^{\circ}\right)$. 
Por lo que se refiere al contenido del servicio público, a la naturaleza de las prestaciones en que consiste, la ubicación del artículo 128 en el capítulo relativo a la Economía y Hacienda, indica que han de tener un carácter preferentemente económico. No es un accidente fortuito el encaje constitucional. Sector público y sector privado son, obviamente, conceptos económicos.

Que la reserva al sector público de un servicio esencial implica la titularidad en exclusiva de la actividad por parte del Estado, que es una nota característica del servicio público desde su nacimiento, se comprende porque aquella expresión significa que una determinada actividad pase del sector privado al sector público, deja de pertenecer al sector privado.

La mera actividad económica del Estado en concurrencia con la de los particulares no implica reserva alguna, sino una iniciativa pública perfectamente legítima, amparada por el primer párrafo del artículo 128, antes citado, sin más limitaciones que el respeto al contenido esencial de la economía de mercado.

La reserva al sector público puede verificarse atribuyendo la titularidad directamente a la Administración del Estado o local ${ }^{13}$, o bien a una persona jurídica que bajo formas distintas, sometidas al Derecho público o al Derecho privado, constituya una empresa pública.

Conviene retener, algo que es importante para la configuración actual del servicio público. La reserva ha de hacerse por ley; o de otro modo la declaración formal del servicio público debe hacerse por ley.

No basta, después de la vigencia de la Constitución, que esa declaración del servicio público se haga por una norma reglamentaria, directamente por la Administración. Esta afirmación, como es obvio, ofrece importantes consecuencias, ya que la historia demuestra con alguna frecuencia que la Administración ha acudido sin habilitación legal expresa a la declaración de servicios

${ }^{13}$ El artículo 86 de la Ley 7/1985, de Bases de Régimen Local, declara la reserva a favor de las Entidades Locales de una serie de actividades o servicios esenciales. El artículo precedente define como "servicios públicos locales cuantos tienden a los fines señalados como de la competencia de las Entidades locales".

Podría entenderse también a la Administración autonómica en determinadas condiciones. Cfr. F.SOSA WAGNER, La gestión de los servicios públicos locales, $5^{\mathrm{a}}$ ed. 2002, p. 37 con otras opiniones. 
públicos de un actividad, con el objeto de poder intervenir en ella, en uso de la potestad discrecional, ya que una numerosa jurisprundecia otorga este carácter a la potestad de organizar los servicios públicos.

Este límite formal tiene su explicación en los otros límites de carácter material. Por un lado, ha de tratarse de servicio esencial y, por otro, debe respetarse el marco de la economía de mercado. Sólo podrá reservarse al sector público (o en la terminología clásica del servicio la titularidad en exclusiva al Estado) una actividad cuando se trate de servicios esenciales y esa esencialidad, como expresión de lo que son las aspiraciones de la sociedad en un momento determinado, debe ser lógica y legítimamente apreciada por sus representantes, que constituyen el Parlamento, y cuya manifestación jurídica es la ley.

Es obvio que no se puede predeterminar las prestaciones que una colectividad considera esenciales. "Hay ahí algo esencialmente variable, evolutivo, desde luego; es hasta difícil fijar el sentido general de esta evolución", decía DUGUIT en $1911^{14}$.

No es fácil ciertamente señalar de antemano los límites, pero sí cabe realizar algunas afirmaciones. Aquellos servicios que no se estiman esenciales no pueden constituir el contenido de un servicio público. Ha de tratarse de actividad económica de prestación, regular y continua.

Por otra parte, juega también en esta declaración de servicio público la protección reforzada que la Constitución española, otorga a los derechos fundamentales. Aparecen, así, como un límite para la iniciativa pública en materia económica y concretamente para la declaración de una actividad como servicio público ${ }^{15}$.

Desde esas premisas pueden analizarse actividades que, en la doctrina y, en ocasiones también por el legislador, se denominan servicios públicos asistenciales o servicios públicos objetivos.

${ }^{14}$ Las transformaciones..., cit. Págs. 34-35.

${ }^{15}$ En esa dirección, P. DEVOLVÉ, "Service publique et libertés publiques", Revue francaise de Droit administratif, 1, 1985, págs. 1 y ss., G. ARIÑO, «Servicio público y libertades públicas», Actualidad y Perspectivas del Derecho Público a fines del siglo xx. Homenaje al profesor Garrido Falla, Madrid, 1984, pp. 1315 y ss. y J.L. MARTÍNEZ LÓPEZ-MUÑIZ. 
No es ya que actividades llevadas a cabo por entes surgidos en la sociedad fuesen asumidas por el Estado y, en ese concepto configuradas como servicios públicos -beneficencia o educación-, sino que esa asunción se realiza en el marco de un Estado social y democrático de Derecho, sin necesidad de calificarlas como servicio público en el sentido concreto en el que lo entendió la inicial formulación jurídica de la categoría, no desmentido por la vigente Constitución.

En algún caso, esa asunción puede calificarse de función del Estado, al nivel de la justicia, como sucede con la seguridad social (art. $41 \mathrm{CE}$ ), superando viejos planteamientos enlazados con los conceptos de beneficencia o asistencia social. No se trata de permitir al Estado que asuma una actividad con la exclusiva de su titularidad. La reserva se realiza directamente por la Constitución. La obligatoriedad de la afiliación y de las cotizaciones, son notas que separan la función del Estado de la idea de servicio público e, incluso, de la más amplia de servicios esenciales. Como un servicio esencial, que el Estado ha de asegurar, cualquiera que sea quién lo preste -el propio Estado o los particulares- pueden entenderse las prestaciones sanitarias (art. $43 \mathrm{CE}$ ) o de educación (art. 27). El Estado tiene la exclusiva de la responsabilidad de garantizar la realización de los derechos respectivos, cuya titularidad corresponde a los ciudadanos.

Precisamente porque no se trata de una exclusiva de la titularidad, incompatible con el reconocimiento de los derechos, no existe concesión para que el servicio sanitario o educativo pueda ser prestado por particulares. Se trata de actividades reguladas por el Estado, de conformidad con estándares mínimos determinados por el Estado. De ahí que se utilice la autorización. El aseguramiento del derecho puede requerir $-\mathrm{y}$ es normal dado el compromiso constitucional- que el Estado realice directamente una actividad administrativa de prestación. Para justificarla no es necesario, ni siquiera procedente, acudir a la teoría acuñada del "servicio público objetivo ${ }^{16 "}$.

\footnotetext{
${ }^{16}$ En la línea de POTOSCHNIG, cit., R. GOMÉZ-FERRER, "El régimen general de los centros privados de enseñanza”, Revista de Administración Pública, 70(1973), págs. 377 y ss. L. PAREJO, "Servicios públicos y servicios de interés general": La renovada actualidad de los primeros, Revista de Derecho de la Unión Europea, no 7 (2004), pp. 64 y ss.

También en contra, de esa categoría, J.M. SALAS ARQUER, "Las concesiones de servicio público en un contexto liberalizado", Revista andaluza de Administración Pública, 56 (2004). Esa noción "supone la confusión de dos conceptos -y dos regímenes jurídicos- perfectamente diferenciados y asentados desde hace años en España, como son el servicio público y la actividad reglamentada que no hay necesidad alguna de asimilar".
} 
El Derecho positivo mantiene la utilización del servicio público en determinados supuestos por inercia doctrinal, de la que no es descartable un posicionamiento ideológico o, sencillamente, la influencia del poder político. Es lo que sucede con la educación o con la radiodifusión y la televisión ${ }^{17}$.

De un lado, el contenido económico, antes señalado como nota definidora de la actividad susceptible de ser configurada como servicio público, no caracteriza decisivamente a la educación. Por lo que atañe a la radiodifusión y a la televisión, si se la adjudicase tal carácter prioritario no estaríamos ante un servicio esencial ${ }^{18}$. La esencialidad podría venir de ser un medio para transmisión de la información. Nos encontramos ante un obstáculo de fondo: el derecho fundamental reconocido en la Constitución (art. 20,1 d) "a comunicar o recibir libremente información por cualquier medio de difusión”. No se ha accedido a esa categoría para la prensa escrita.

Para garantizar esos derechos fundamentales el Estado no tiene que acudir a declarar la actividad de prestación correspondiente como servicio público. No precisa la técnica de servicio público para situar en la órbita de su intervención o regulación una determinada actividad. Coexisten iniciativa pública y privada para la creación de centros docentes que hagan real el derecho fundamental reconocido constitucionalmente. Lo mismo puede afirmarse de la televisión, aunque en el artículo 20 de la CE no se habla explícitamente de la creación de instrumentos para garantizar el derecho, por razones que se explican en los debates parlamentarios ${ }^{19}$.

El protagonismo público viene reclamado por la garantía de realización del derecho fundamental o, también, como en el caso de la radiodifusión y televisión, por las circunstancias técnicas, incluido el dominio público, en que han de desarrollarse las prestaciones. Nada impediría, sin embargo, que ese protagonismo se manifestase en una adecuada regulación, en la que se salvaguardasen los principios de la libre concurrencia.

\footnotetext{
${ }^{17} \mathrm{El}$ artículo $1^{\circ}$ de la ley 4/1980 de 10 de enero sobre el Estatuto de la radio y la televisión declara taxativamente: "la radiodifusión y la televisión son servicios públicos esenciales cuya titularidad corresponde al Estado".

${ }^{18}$ Cfr. F. SAINZ MORENO, "La televisión en Europa”, nº 2 Cortes Generales, 1988, pp. 35-36.

${ }^{19}$ Cfr. Constitución española. Trabajos parlamentarios, I, Cortes Generales, 1980 pp. $142-43$.
} 
El propio Tribunal Constitucional, en una doctrina revisable, ha reconocido que "la configuración de la televisión como servicio público, aunque no sea una afirmación necesaria en nuestro orden jurídico- político, se encuentra dentro de los poderes del legislador" (STC 12/1982). En la misma línea insiste en que el servicio público "es una técnica que -al igual que otra constitucionalmente posible- puede permitir al legislador ordenar una adecuada concurrencia de las televisiones públicas y las distintas televisiones privadas" (STC 127/1994).

Nos encontramos ante una situación que no es definitiva, que el propio Tribunal Constitucional certifica al reconocer "los cambios en los condicionamientos técnicos" (STC 88/1995 de 6 de junio). La televisión por cable evidencia la endeblez de la justificación de la exclusiva de titularidad estatal ${ }^{20}$. El propio legislador la constata. En ese sentido, la ley 22/1999 de 7 de junio que modifica la ley 25/1994 de 12 de julio, por transposición de la directiva 97/36/CE, sobre coordinación de disposiciones legales, reglamentarias y administrativas de los Estados miembros, suprimía la anterior alusión a "las entidades que prestan el servicio público de televisión" porque "desde la entrada en vigor de la ley 37/1995 de 12 de diciembre de Telecomunicaciones por Satélite existen en España servicios de televisión que no tienen la consideración de servicio público ${ }^{21}$ ".

Discutible es que la legitimidad del uso de la categoría se justifique en que es necesaria para garantizar derechos fundamentales (STC 206/1990 de 13 de diciembre). Más bien choca con la titularidad del derecho fundamental reconocido en el artículo 20,1 d ${ }^{22}$. El artículo 10 del convenio europeo para la protección de los derechos humanos y libertades fundamentales reconoce el mismo derecho añadiendo que ello no impide "que los Estados sometan a las empresas de radiodifusión, de cinematografía o de televisión a un régimen de $a u$ torización privada", obviamente distinto de la concesión, ligada al servicio público, como gestión indirecta del mismo ${ }^{23}$.

${ }^{20}$ Cfr. M. CALVO CHARRO, La televisión por cable, Madrid, 1997, pp. 83 y ss.

${ }^{21}$ Efectivamente el artículo 1.1 de Ley 37/1995 declara que los servicios de telecomunicaciones "para cuya prestación se utilicen de forma principal redes de satélites de comunicación no tendrán la consideración de servicio público".

${ }^{22}$ Cfr. F. GONZÁLEZ NAVARRO, Televisión privada y televisión pública, Civitas, Madrid, 1982.

${ }^{23} \mathrm{El}$ instrumento de ratificación del convenio, 26 de septiembre de 1979, anterior al Estatuto de redio y televisión, incluye una declaración interpretando que ese régimen de autorización previo es compatible con lo dispuesto en el ordenamiento español. Cfr. J.M. SALAS ARQUER, op. cit. loc. cit. 
Ni los condicionamientos técnicos -que en algunos casos no existen- ni la garantía de los derechos fundamentales justifican la necesidad de la opción, a la luz de la interpretación que se ha hecho del artículo 128 de la Constitución ${ }^{24}$.

La situación actual se ilumina al considerar la evolución legislativa del sector $^{25}$. La ley de 26 de octubre de $1907^{26}$ y, sobre todo, el Real Decreto de 24 de enero de 1908 dictado para su desarrollo, contienen la reserva a favor del Estado, de la radiodifusión y la televisión.

La ley antes citada autorizaba al Gobierno para plantear y desarrollar los servicios de radiotelegrafía, cables y teléfonos. El Real Decreto especificaba en su artículo $1^{\circ}$ que se consideraban comprendidos "entre los monopolios del Estado relativos al servicio de toda clase de comunicaciones eléctricas, el establecimiento y explotación de todos los sistemas y aparatos aplicables a la llamada telegrafía hertziana, "telegrafía eléctrica", "radiotelegrafía" y demás procedimientos similares, ya inventados o que puedan inventarse en el porvenir".

Consecuentemente, el Real Decreto de 27 de enero de 1923 establecía en su artículo $1^{\underline{a}}$ que todas las instalaciones radioeléctricas constituyen un monopolio del Estado, especificándose dentro de ellas, ya de una manera precisa, las estaciones de radiodifusión ${ }^{27}$.

\footnotetext{
${ }^{24}$ Una crítica de la jurisprudencia constitucional en S. MUÑOZ MACHADO, Servicio público y mercado, III, La televisión, Civitas, Madrid, 1998, pp. 135 y ss. aunque acepte una concepción amplia del servicio público en el sentido de no requerir la exclusiva de la titularidad y salvar así la concurrencia entre Administración y particulares, como en la enseñanza o la sanidad (p. 146).

${ }^{25}$ Cfr. J.L. MEILÁN, La cláusula..., pp. 86-88. La reserva legal previa era una manifestación de la potestad discrecional para organizar los servicios públicos, que quedarían dentro de la denominada potestad doméstica de la Administración. Con la reserva se pretende evitar colisiones futuras de intereses públicos o privados.

${ }^{26} \mathrm{El}$ art. $1^{\circ}$ de la Ley autorizaba al Gobierno para que por Decreto reorganizase los servicios de "radiotelegrafía, cables y teléfonos". El profesor VILLAR PALASí habla en este caso de "publicatio ad cautelam". Cfr. Intervencion..., cit., p. 240.

${ }^{27}$ En torno a 1924 tiene lugar la consagración del monopolio en la organización de los servicios públicos. El tenor del art. $1^{\circ}$ de la disposición que se menciona en el texto es una prueba más: "Todas las instalaciones radioeléctricas constituyen un monopolio del Estado y desde la publicación de este Real Decreto quedan terminantemente prohibidas aquellas estaciones transmisoras y receptoras, o simplemente receptoras, que no sean debidamente autorizadas por el Ministro de la Gobernación o, en su nombre, por el Director general de Comunicaciones".
} 
La ley 26 de junio de 1934 volverá a insistir en que el servicio de radiodifusión nacional es "una función esencial y privativa del Estado 28 ".

El Decreto de 22 de noviembre de 1935 ofrece ya en su redacción un atisbo de reservar la televisión al Estado. En su artículo 1.o considera comprendidos entre los servicios de radiocomunicación del Estado "el establecimiento y explotación de los de radiodifusión de sonidos e imágenes ya en uso o que puedan inventarse en el porvenir" (art.1).

El Decreto de 14 de noviembre de 1952 hablará, en concreto, del servicio público de radiodifusión, y hará referencia en su exposición de motivos a que el sistema imperante en la mayoría de los países, a pesar de las diferencias del régimen político, es el de monopolio o de propiedad del Estado.

Se trata de una regulación de base regaliana, en la que el monopolio juega un papel fundamental, no ya desde la titularidad -que suponía la reservasino de su gestión. El monopolio estatal no puede ser característica de una actividad que constituye el contenido de un derecho fundamental. No existe monopolio porque no existe titularidad en exclusiva de actividad por el Estado ${ }^{29}$.

La Constitución de 1978 no ha afectado a la categoría del servicio público tal como se ha venido razonando, en el ámbito local. El artículo 85 de la ley reguladora de las bases de régimen local de 2 de abril de 1985 contiene una amplia denominación de los servicios públicos locales, entendiendo por tales "cuantos tienden a la consecución de los fines señalados como de la competencia de las entidades locales". Estaría en la línea de identificarlos con toda la actividad administrativa. De todos modos, de lo expresado respecto de la gestión puede deducirse un concepto restringido en la línea de lo aquí defendido, con la exégesis del venerable Reglamento de servicios de las Corporaciones locales de 1955 y lo dispuesto en la ley de contratos de las Administraciones Públicas (texto refundido aprobado por el Real Decreto legislativo 2/200 de 16 de junio), de aplicación a la Administración local según el artículo 1,2.

\footnotetext{
${ }^{28}$ Art. $1^{\circ}$. Cfr. También art. 5. ํㅜㄴ
}

29 De momento se combate el monopolio de la gestión en un voto particular a la STC 127/1994 del Magistrado Gabaldón. Admitiendo la naturaleza de servicio público, su gestión que "implica el ejercicio de derechos fundamentales de los ciudadanos no puede organizarse en forma de monopolio estatal que impida absolutamente el ejercicio del derecho". 
Un criterio definitorio del servicio público, es la asunción de la titularidad por la Administración y el contenido económico de la actividad que la hace susceptible de ser gestionada indirectamente. Por eso no pueden gestionarse de esta manera, sino que "serán atendidas necesariamente por gestión directa las funciones que impliquen ejercicio de autoridad" (artículos 43 y 69,1 del RSCL, en concordancia con el 155 del TRLCAP). La admisión expresa del servicio público se contiene en el artículo 114 del citado Reglamento, ligado a la posibilidad de prestación mediante concesión administrativa, que está vedada a lo servicios relacionados con actividades benéficas, que podrán prestarse por gestión directa o por concierto.

El artículo 86,3 de la LBRL ofrece un argumento concluyente para la tesis aquí defendida, al declarar la reserva a favor de las entidades locales de una serie de "actividades o servicios esenciales", algunos de una larga tradición municipal. ${ }^{30}$, con una expresión equivalente a la del artículo 128,2, in fine de la Constitución $^{31}$, en la que se ha identificado la categoría del servicio público.

\section{EL IMPACTO DEL DERECHO COMUNITARIO}

El Derecho comunitario se construye en el ambiente de liberalizaciones y privatizaciones de actividades configuradas como servicios públicos, en su sentido estricto de titularidad estatal, aunque su gestión fuese llevada por particulares. Su condición, además, de "meeting point" de ordenamientos diferentes, donde la categoría de servicio público o tenía un papel dominante o sencillamente se desconocía obligó a soluciones de compromiso, exteriorizadas de diferente manera, que reflejan vaivenes característicos de los momentos políticos ${ }^{32}$.

Ese equilibrio queda reflejado en el Tratado y ha sido calificado de "contradicción de fondo entre la previsión puntual del mercado común y de un ré-

\footnotetext{
30 Abastecimiento y depuración de aguas, recogida, tratamiento y aprovechamiento de residuos, mataderos, mercados y lonjas centrales, transporte público de viajeros. Los servicios funerarios, fueron liberalizados por R. D. ley 7/1996 de 7 de junio, consolidado por resolución de 10 de junio.

31 Cfr. J.L. RIVERO YSERN, Manual de Derecho local, $5^{\mathbf{a}}$ Ed., Madrid, 2004, p. 440, F. SOSA WAGNER, La gestión de los servicios públicos locales, $5^{\underline{a}}$ Ed. Madrid, 2002, p. 44 y ss.

32 Cfr. En la biblibografía española, M.A. SENDÍN GARCÍA, Hacia un servicio público europeo. El nuevo derecho de los servicios públicos, Granada, 2003.
} 
gimen de confianza y el mantenimiento de elecciones de política económica por los Estados" ${ }^{33}$, que permite una cierta pervivencia del servicio público en lo esencial de su configuración jurídica.

Para lo que aquí interesa conviene recordar que la expresión "servicio público" aparece en el actual artículo 73 del Tratado (antiguo 77) al referirse a las ayudas públicas, permitidas como excepción, "que correspondan al reembolso de determinadas obligaciones inherentes a la noción de servicio público". Referencia familiar para los ordenamientos que admiten la categoría y cuyo alcance habrá que interpretar para los que la desconocen.

El artículo 86,2 del Tratado se refiere a "servicios de interés económico general". Las empresas encargadas de su gestión -sean públicas o privadasquedan sometidas a la regla de la competencia, en la medida que su aplicación "no impida de hecho o de derecho, el cumplimiento de la misión específica a ellas confiada”.

Aunque resulte paradójico, el primero de los preceptos citados implica una menor aceptación de la categoría de servicio público que el segundo. Se refiere sólo a determinadas obligaciones que el gestor privado de un servicio de transportes ha de desarrollar en función del interés general que ha de asegurar el Estado para garantizar "el servicio universal ${ }^{34 "}$.

El segundo precepto no impide la subsistencia del servicio público, tal como se viene sosteniendo, de titularidad estatal. Será cuestión de opción política y de justificación jurídica de la opción. En ese sentido no habría obstáculo para la pervivencia del servicio público, como servicio de interés económico general, siempre que esté justificada la excepción respecto de la aplicación de las reglas de la competencia ${ }^{35}$. La tesis viene avalada por el artículo 36 de la Carta de los derechos fundamentales de la Unión Europea proclamada en

33 Conclusiones del Abogado General Tesauro de 13-II-1990 en asunto 202/88, S. 19-III-1991.

${ }^{34}$ El servicio universal completa la noción de servicio público según Jean Yves CHEROT, AJDA, 3 (1996), p. 177.

${ }^{35}$ En el sentido de lo expuesto, J.L. MARTÍNEZ LÓPEZ-MUÑIZ, "Servicio público, servicio universal y obligación de servicio público en la perspectiva del Derecho comunitario: los servicios esenciales y sus regímenes alternativos" en Os caminhos da privatizaçao da Administración Pública, Coimbra, 2001 pp. 250 y ss. 
el Consejo europeo de Niza, según el cual "la Unión reconoce y respeta el acceso a los servicios de interés económico general, tal como disponen las legislaciones y prácticas nacionales, de conformidad con el Tratado constitutivo de la Comunidad Europea, con el fin de promover la cohesión social y territorial de la Unión".

El régimen excepcional respecto de las reglas de la competencia que implican los servicios públicos -de titularidad estatal- coincide en su finalidad con la prestación de servicios que no respondan a esa reserva de titularidad. El interés general es el procurado en todo caso. Por eso, el artículo 16 del Tratado reconoce la importancia de los servicios de interés general, por el fin que persiguen, al situarlos "entre los valores comunes de la Unión". No significa la autorización del servicio público, pero tampoco su erradicación.

Los documentos de la UE, en aras del equilibrio que deben mantener entre concepciones jurídicas diferentes utilizan, en ocasiones, la expresión servicio público con un sentido deliberadamente genérico. Las obligaciones de servicio público se interpretan como "obligaciones de interés general", se dice, y en el mismo documento se afirma que "la Comunidad protege los objetivos de interés general y la misión de servicio público ${ }^{36 "}$.

El libro Blanco sobre los servicios de interés general, se apresura a determinar que los términos de "servicios de interés general" y "servicios de interés económico general", no deben confundirse con la expresión "servicio público", que tiene diferentes significados ${ }^{37}$.

La expresión "servicios de interés general" no figura en el Tratado. Como se reconoce en documentos oficiales de la UE, se ha acuñado en la práctica comunitaria. Es más amplia que la de "servicios económicos de interés general", porque incluye actividades de contenido no económico, pero que se "consideran de interés general y sometidas a obligaciones específicas de servicio público ${ }^{38 ”}$. Pese a la dificultad de definir con generalidad y absoluta pre-

\footnotetext{
36 Comunicación de la Comisión-Los servicios de interés general en Europa, Diario Oficial, C 017 de $19 / 1 / 2001$.

37 Libro Blanco sobre los servicios de interés general, COM/2004.

${ }^{38}$ Libro verde... cit. p. 15.
} 
cisión servicios económicos y no económicos ${ }^{39}$, los medios comunitarios no dudan en calificar entre los primeros, y en todo caso, no como servicios económicos de interés general, la educación nacional, los regímenes básicos de seguridad social obligatorios, la sanidad ${ }^{40}$. Una confirmación, a mi juicio, de lo expuesto para el Derecho español al rechazar dentro de la categoría jurídica de servicio público, los servicios asistenciales y similares ${ }^{41}$.

No han cambiado las categorías, ni la responsabilidad del Estado para asegurar la satisfacción de necesidades colectivas; lo que ha cambiado, como se recuerda desde la UE, "es la forma en que los poderes públicos cumplen sus obligaciones con los ciudadanos". Ha cambiado el desarrollo de la sociedad, tanto desde el punto de vista del reconocimiento y exigencia de los derechos de los ciudadanos en un Estado social y democrático, como desde su capacidad para realizar eficazmente las actividades que los requieren, la capacidad del mercado.

El servicio público nació para satisfacer necesidades de la sociedad. La misma finalidad que justifica los servicios económicos de interés general, configurados en el Derecho comunitario, ahora más acentuada, porque se trata de garantizar unos derechos de acceso y asequibilidad a todos los ciudadanos. Es lo que explica que, por vía jurisprudencial, aceptada normativamente, se haya acuñado el concepto de "servicio universal", como una de las obligaciones de servicio público o de interés general.

\footnotetext{
${ }^{39}$ Actividad económica es "cualquier actividad consistente en ofrecer bienes o servicios en un determinado mercado”. E-180-184/98.

${ }^{40}$ Cfr. STJ de 22 de enero de 2002, asunto C-218/00, INAIL, y jurisprudencia allí citada. La gestión de la seguridad social, en este caso de una de sus ramas como el seguro de accidentes laborales y enfermedades profesionales "no es un actividad económica"; el INAIL, Instituto que la desarrolla, "cumple una función de carácter exclusivamente social" y no es de aplicación el artículo 86 del Tratado. Anteriormente y en el mismo sentido S.T.J. de 17 de febrero de 1993 asuntos acumulados C-159/91 y 160/91, Poucet. Las entidades gestoras del seguro de enfermedad desempeñan una función de carácter exclusivamente social. Tal actividad se basa en el principio de solidaridad social y carece de finalidad lucrativa, que es determinante para concluir que no es una actividad económica.

${ }^{41}$ Un servicio obligatorio de vigilancia y rápida intervención para proteger el dominio marítimo contra contaminaciones por vertidos "no tiene un carácter económico que justifique la aplicación de las normas sobre la competencia del Tratado". Se trata de "una misión de interés general que forma parte de las funciones esenciales del Estado en materia de protección del medio ambiente STJ de 18 de marzo de 1997, asunto C-343/95, Porto di Genova.
} 
Se declara que "la definición de una misión específica de interés general y del consiguiente servicio necesario para cumplir dicha misión no implica necesariamente un método específico de prestación de servicios ${ }^{42 "}{ }^{2}$. El servicio universal no requiere que se preste por la Administración directamente, ni se reserve su titularidad. Serán, ordinariamente, los operadores del servicio los que deban cumplir las obligaciones de interés general, con otorgamiento o no de derechos especiales o exclusivos ${ }^{43}$, cuya justificación puede ser controvertida $^{44}$, entendiéndose que la compensación es compatible con el Tratado ${ }^{45}$.

La definición que se contiene en el artículo 2,3 de la Directiva 2004/17/Ce sobre la coordinación de los procedimientos de adjudicación de los contratos en los sectores del agua, de la energía, de los transportes y de los servicios postales, en cuanto que limitan a una o más entidades el ejercicio de una actividad referida a esos sectores, afectando sustancialmente a la capacidad de las demás entidades de ejercer dicha actividad, entiendo que es una configuración de la técnica del servicio público, en cuanto se elimina la competencia, propia del mercado, por un acto de imperio que revela la asunción de la titularidad por la Administración. El prestador del servicio, en la parte delimitada a que hace referencia el derecho exclusivo, se convierte en concesionario, aunque el sector en conjunto, responda a las reglas del mercado y la competencia, como actividad privada regulada, y de interés general. Y todo ello modulado por situaciones o regímenes de transición a la competencia.

${ }^{42}$ Los servicios de interés general..., cit., $\mathrm{n}^{\mathrm{o}} 14$.

43 El Dictamen del Comité económico y social sobre "los servicios de interés general 11(1999/C368/117) define los derechos exclusivos como: "los derechos garantizados por un Estado miembro que reservan la prestación de determinados servicios a una empresa mediante disposiciones legales, reglamentarias o administrativas, reservándole el derecho a prestar un servicio o a desempeñar una actividad en un área geográfica dada." La STJ de 25 de octubre de 2001 declara reconocimiento de derechos exclusivos de transporte de enfermos en ambulancias, como una misión de interés general.

Cfr. STJ de 19 de mayo de 1993, cit. Asunto Corbeau sobre correo; STJ 10 de diciembre de 1991, Porto di Genova, sobre operaciones portuarias, Asunto d'Almello de 27 de abril 1994, sobre distribución de energía eléctrica.

En la misma línea, la corrección de limitar el número de empresas especialmente seleccionadas para resolver un problema medioambiental por la falta de capacidad de tratamiento de los residuos de la construcción no peligrosos destinados a su valorización STJ. 23 de mayo de 2000 asunto C-209/98. Cfr. Art. 2,3 de la Directiva 2004/17/CE citada.

Cfr. Directiva 2000/52/CE de 26 de julio.

${ }^{44}$ S.11 abril 1989, C-66/86 Silver Line Reisebüro; S. 23 abril 1991, C-41/90, Höfner; S. 8 julio 1999, T- 266/97, Ulaamse Televisie Maatshappi.

45 S.TJ 24 julio 2003, C- 280/00, AltmarkTrans que sienta una nueva doctrina. 
A su vez el artículo 3 de la Directiva 2004/18/CE reconoce que el poder adjudicador puede otorgar derechos especiales o exclusivos para el ejercicio de una actividad de servicio público, respetando el principio de no discriminación por razones de nacionalidad.

La universalidad que se predica de los servicios económicos de interés general vendría a coincidir con la esencialidad de los servicios del artículo 128 de la CE. Son servicios esenciales. Sólo cuando se opere con exclusividad, que se admite, nos encontraríamos con el servicio público que aquí se viene sosteniendo ${ }^{46}$.

Ciertamente los Estados miembros tienen libertad en lo que se refiere a la definición y práctica de las obligaciones de servicio público, pero no es menos cierto que para cumplir con ellas, la exención a las reglas de la competencia ha de ser interpretada en un sentido restrictivo, reducida a lo estrictamente necesario para cumplir la misión de interés general ${ }^{47}$. En otros términos, el servicio económico de interés general, de titularidad reservada al Estado, con su connotación de universalidad, es una excepción en el panorama comunitario, pero subsiste como tal. Es una opción limitada, pero libre, del Estado miembro de la UE.

No ha desaparecido el servicio público, ni ha cambiado como categoría jurídica, tal como puede configurarse desde la perspectiva constitucional. Otra cosa es que se haya reducido su ámbito de aplicación. Actividades que durante muchos años han sido realizadas como auténticos servicios públicos hoy se prestan sin necesidad de acudir a esa categoría jurídica. Son actividades desarrolladas por particulares en el ámbito y las reglas del mercado y reguladas por el Estado, que puede imponerles obligaciones que exceden de aquel, con compensación o sin ella. Así ha sucedido en varios sectores ${ }^{48}$.

\footnotetext{
${ }^{46}$ Cfr. J.L. MARTÍNEZ LÓPEZ-MUÑIZ, op. cit., pp. 271 y ss.
}

${ }^{47}$ Cfr. S. GONZÁLEZ -VARAS IBÁÑEZ, "Del servicio público a los mercados de interés general" en "Cuadernos de Derecho Público" no 12 (2001) p. 64 que se refiere a las obligaciones de servicio público como un régimen de excepción.

${ }^{48}$ Cfr. Exposición de Motivos de la ley 54/1997 de 27 de noviembre: "No se considera necesario que el Estado se reserve para sí el ejercicio de ninguna de las actividades que integran el suministro eléctrico. Así se abandona la noción de servicio público". En análoga dirección, la Ley 34/1998 de 7 de octubre, del sector de Hidrocarburos ("se suprime en el sector del gas la consideración de servicio público”); la Ley 48/2003 de 26 de noviembre sobre Puertos de interés general; la ley 39/2003 de 17 de noviembre del sector ferroviario: "el transporte ferroviario es un servicio de interés general y esencial para la comunidad... se prestará en régimen de libre competencia” (art. 42,2) en contraste con el artículo 150 de la ley 16/1987 no formalmente derogado. 
Nada impide tampoco que una parte del sector económico, precisamente como servicio universal, pueda ser desarrollada como un auténtico servicio público $^{49}$. No era una nota esencial al concepto de servicio público que toda la actividad de un sector económico, aunque fuese frecuente, fuese desarrollada bajo aquella categoría, como tradicionalmente ha sucedido en el de la electricidad, donde ha podido configurarse de diferente modo la producción y la distribución ${ }^{50}$. Es la solución que se ha adoptado, por ejemplo, para los servicios reservados al operador al que se encomienda la prestación del servicio postal universal ${ }^{51}$ o los que desarrollen actividades para la defensa nacional ${ }^{52}$ en el sector liberalizado de telecomunicaciones, de conformidad con el artículo 296 del Tratado.

El Estado puede hacer uso del margen que le ofrece el Derecho comunitario para el mantenimiento de la categoría del servicio público, caso de los transportes y de la Administración local ${ }^{53}$, o para utilizarla después de libera-

\footnotetext{
${ }^{49}$ La STS 16 de octubre de 2001 (Ar. 2003/2317) reconoce la simultaneidad de imposición de obligaciones de servicio público con contrato de gestión de un servicio público, en materia de transporte marítimo, de conformidad con la STJ de 20 de febrero de 2001 que resuelve una cuestión prejudicial planteada por el Tribunal español.
}

${ }^{50}$ Cfr. F. SOSA WAGNER, La gestión..., cit., habla de publicatio fraccionada, limitada a algunas concretas y específicas funciones. (p. 73). J. SALAS, Régimen jurídico-administrativo de la energía eléctrica, Madrid-Bolonia, 1997, p. 36; J. TRILLO FIGUEROA-F. LÓPEZ-JURADO, La regulación del sector eléctrico, Madrid 1996, pp. 160-2. Como servicio público que abarca todo el sector G. ARIÑO-L. LÓPEZ CASTRO, El sistema eléctrico español. Regulación y competencia, Madrid, 1998, pp. 103 y ss.

${ }^{51}$ Art. 4 de la Ley 24/1998 de 13 de julio: comprende servicio de giro y envíos de cartas, tarjetas y paquetes hasta un determinado peso. Está en la línea de la comentada STJ de 19 de mayo de 1993, Corbeau C-320/91: los servicios específicos son compatibles con el "servicio postal tradicional", es decir, "el servicio de interés económico general del que se hace cargo el titular del derecho exclusivo".

${ }^{52}$ Art. 2,2 y 4 de la Ley 32/2003 de 3 de diciembre.

${ }^{53}$ El protocolo sobre el sistema de radiodifusión público, anejo al Tratado de Ámsterdam, se refiere específicamente al "servicio público de radiodifusión".

El Reglamento CEE 3577/1992 de 7 de diciembre, por ejemplo, deja a los Estados miembros la opción de "celebrar contratos de servicio público o de imponer obligaciones de servicio público" en materia de determinados tráficos marítimos.

En materia de transportes terrestres (ley 16/1987) su artículo 69 sigue utilizando la categoría, que aparece en el artículo 3, c de la Ley 48/1998 de 30 de diciembre en relación con la "la explotación de redes que prestan un servicio público por ferrocarril (sic) sistemas automáticos, tranvía, trolebús, autobús o cable". 
lizar una actividad o incluso para restablecerla ${ }^{54}$, sin que tenga que acudir a una defensa casi numantina como la llevada a cabo, a veces, en la doctrina francesa ${ }^{55}$.

\section{RECAPITULACIÓN}

La legislación española que ha transpuesto Directivas europeas, define con toda naturalidad como servicios de interés general los de Sectores liberalizados de contenido económico, como el de telecomunicaciones, o el eléctrico, o de un modo equivalente, puertos, hidrocarburos, postal, ferrocarriles, anteriormente calificados como servicios públicos, en el sentido estricto y propio, a mi entender, del ordenamiento jurídico español.

Entiendo que no ha surgido un "nuevo servicio público", pese a lo sugerente del enunciado ${ }^{56}$.

Por lo que se refiere a la Administración local, Cfr. Artículos 85 y 86 de la LBRL y lo expresado anteriormente en el texto.

Se ha llegado a hablar de un nuevo servicio público en relación con redes inalámbricas por Mercedes FUERTES, Redes inalámbricas municipales, Madrid, 2005.

El artículo 4,5 de la Ley 32/2003 de telecomunicaciones prevé la posibilidad de que "el Gobierno con carácter excepcional y transitorio podrá acordar la asunción por la Administración General del Estado de la gestión directa de determinados servicios o de la explotación de ciertas redes de comunicaciones electrónicas, de acuerdo con el texto refundido de la ley de contratos de las Administraciones Públicas". Esta referencia parece implicar una calificación subconsciente de servicio público, en el sentido del artículo 155,2, aunque en realidad se trata de una intervención de las previstas en el artículo 128,2 in fine, de la Constitución, por razones de interés general y no por incumplimiento del contratista, concesionario de un inexistente servicio público que la ley no admite. Parece que el espíritu del anterior servicio público sobrevuela inconscientemente sobre el legislador.

${ }^{54}$ En ese sentido, la ley 48/2003 de 26 de noviembre liberaliza los servicios portuarios básicos, abandona la "hasta ahora reservada titularidad de los servicios portuarios a favor de las Autoridades Portuarias" lo que no impide que ante ausencia o insuficiencia de la iniciativa privada, esa Autoridades los presten directa o indirectamente. Y cabe también la revisión de la ley en esta dirección promovida por el Gobierno.

${ }^{55}$ Se ha llegado a hablar de "elemento de la identidad nacional" (J.M. PONTIER). Cfr., a título de ejemplo, el número especial de AJDA, no 46; "Rapport public" en Etudes et Documents, Conseil d'Etat no 46; AJDA, no3 (1996) "Services d'interêt économique géneral", artículos de Cherot y Debéne y Raymundie.

Un intento de aproximación entre el Derecho francés y alemán en M. BULLINGER, "El servicio público francés y la Daseinvorsorge en Alemania”, RAP, 166 (2005) pp. 29-49

${ }^{56}$ Cfr. G. ARIÑO, J.M. DE LA CUÉTARA, J.L, MARTÍNEZ LÓPEZ-MUÑIZ, El nuevo servicio público, M. Pons, Madrid, 1997. 
El servicio público, como categoría o como técnica jurídica para satisfacer necesidades o demandas de la sociedad -el interés general- no tiene la utilidad con la que se creó. En el momento presente, y singularmente en el ámbito europeo, en una de cuyas porciones nació y se desarrolló, es patente esa afirmación ${ }^{57}$. No es necesaria la publicatio; basta con la regulación, más compleja que las autorizaciones puntuales.

Tampoco eso es nuevo como solución alternativa al servicio público. Como testimonio de ello se reproduce algo de lo que decía en 1968, en relación con las innovaciones que requiere el progreso tecnológico, y que se ha intensificado con una creciente preocupación por proveer el medio ambiente ${ }^{58}$ :

"La historia de la evolución en que nos encontramos se caracteriza por el empleo de simples medidas de policía -empleando el término en sentido amplio- para conseguir el mismo objetivo a que respondía la cláusula de progreso implícita en los servicios públicos o la potestad discrecional en la organización de los mismos.

El progreso se consigue sin necesidad de que el Estado declare pública la actividad correspondiente. El título de intervención del servicio público es innecesario; basta la imposición unilateral característica de la técnica de policía ${ }^{59 "}$.

\footnotetext{
${ }^{57}$ Lo reconoce el propio ARIÑO (op cit., p. 24) y T. RAMÓN FERNÁNDEZ, op. cit., loc. cit., pp. 59-62.

58 Cfr. J. ESTEVE PARDO, Técnica, riesgo y Derecho, Barcelona, 1999, pp. 92 y ss.

59 Cfr. J.L.MEILÁN, La cláusula..., pág. 89.
} 